\title{
Evaluation of Seismic Events Occurred after Filling and Drawdown of the Reservoir at Song Tranh 2 HPP in Vietnam
}

\author{
Nghia Quoc Trinh and Krishna Kanta Panthi
}

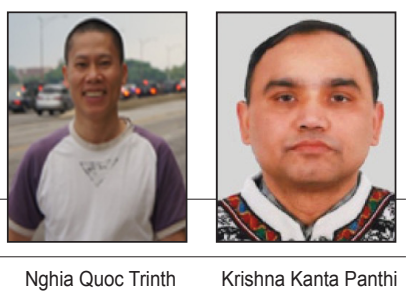

\begin{abstract}
Reservoir-induced earthquakes are a challenging issue for hydropower, and have occurred at many sites around the world. However, each event is unique in itself and depends on the geo-tectonics and geo-hydrology of the area in which the event is situated. This article focuses on seismic events at the Song Tranh 2 hydropower project located in Quang Nam province, Vietnam. The construction of the 96 meter high Roller Compacted Concrete (RCC) dam of this project was completed in August 2011. Approximately one year after commissioning, the dam began experiencing a serious leakage problem through the dam body. In addition, a series of earthquakes occurred near the project area, and continued for several months. The high intensity and magnitude of the earthquakes caused damage to the project and promoted fear among the local people living in the downstream valley. The issues drew significant media attention and thousands of articles about this project were written within a short time. As a result, dam authorities have been subject to extreme public pressure.

This paper describes the earthquake events and difficult situation that both the local population and authorities faced in its aftermath. In addition, we analyze seismic events qualitatively,using data and information on the water filling and drawdown processes. Our analysis provides an insight into these seismic events, as we reconstruct the earthquake scenarios and test a hypothesis of earthquake occurrence. Future earthquake activities are also predicted and compared.
\end{abstract}

Key words: Reservoir, hydropower, earthquake, Vietnam

\section{Introduction}

Heineering geological conditions in reservoirs geological conditions sometimes win the contest. This paper describes and analyzes one such challenge faced at the Song Tranh 2 Hydropower Project (ST2 HPP) in Vietnam, where repeated seismic events occurred after reservoir filling and drawdown. It is established that reservoir-induced earthquakes have occurred in many places in the world and we may glean a lot of information from these events. The most important thing to be noted is that each project is unique as well as the seismic activities that sometimes accompany and follow construction. Each of these events provides new insight and knowledge for engineers.

According to Gupta (2002), reservoir induced earthquakes have occurred in more than 90 reservoirs worldwide up to 2002. The map indicating regions where reservoir induced earthquakes occurred is maintained by International Rivers (2014). Much research has tried to study the phenomenon called "reservoir induced seismicity" (RIS). In most of studies, a general conclusion has been drawn that the earthquake occurs when reservoirs change the water pressure into the rock mass below (pore pressure diffusion) to such an extent that destabilizes the geological structure around the dam, leading to a slip in the structure, causing earthquakes of different magnitudes. This theory was first posed by Talwani in 1997:" In most cases of reservoir-induced seismicity, seismicity follows the impoundment, large lake-level changes, or filling at a later time above the highest water level achieved until then. This has been classified as initial seismicity. This 'initial seismicity' is ascribable to the coupled poroelastic response of the reservoir to initial filling or water level changes" and that "The initial seismicity results from the instantaneous effect of loading (or unloading) and the delayed effect of pore pressure diffusion" (1997:474)

The remainder of our article seeks to test Talwani's theory in the case of the Song Tranh 2 Hydropower

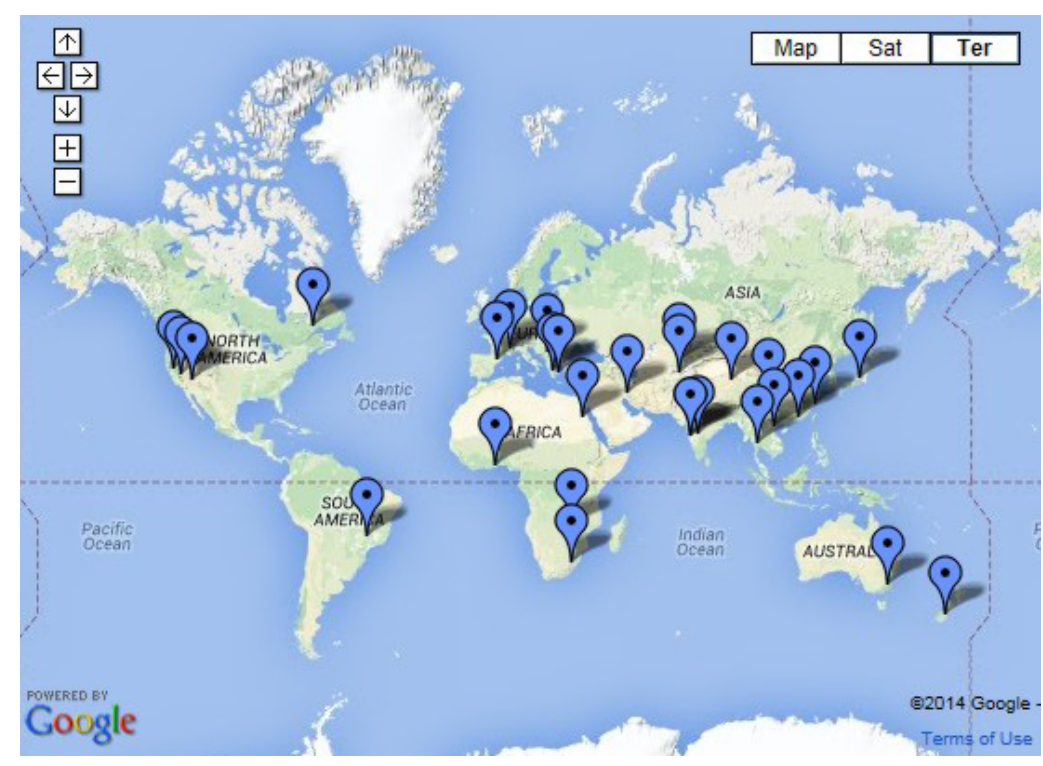

Figure 1: Map indicating regions where reservoir included earthquicks occured 


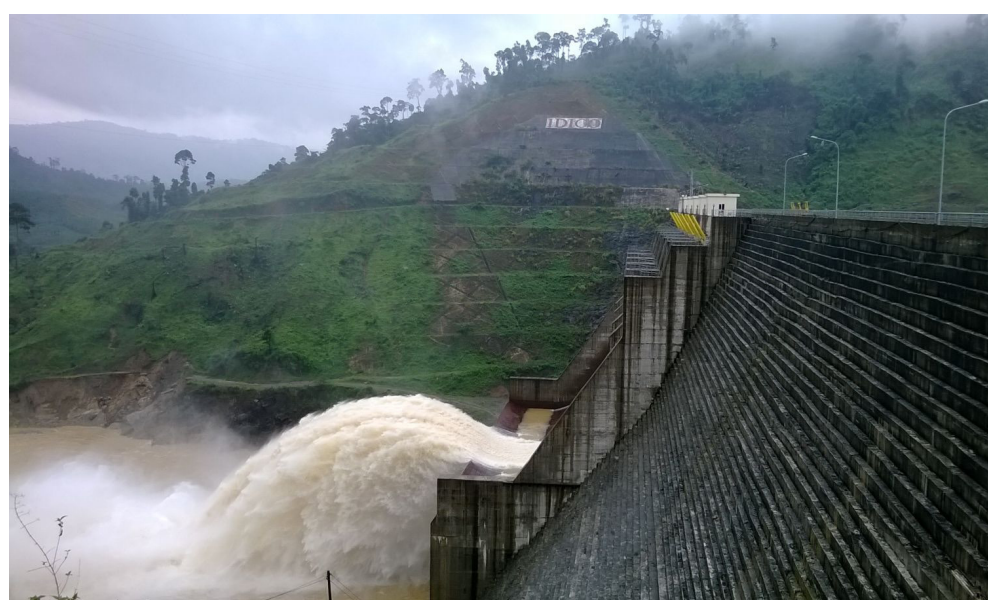

Figure 2: Roller compacted concrete (RCC) main dam at ST2 HPP. northeast block is recognized as part of the former Chinese continent.The stratigraphy and igneous rocks range from the late Proterozoic to Quaternary.The northwest and Truongson blocks are recognized as NW-SE trending Paleozoic folded systems, but there are some differences in tectonic development between them,especially in the Late Paleozoic. The Kontum block is an uplifted massif. The oldest stratigraphy of the Archean is found there. The Nambo blockis a part of the Malaysia - Miami geo-synclinal system, which is recognized as a continental rift filled with thick $(\sim 6 \mathrm{~km})$ Cenozoic deposits (Nam 1995).

ST2 HPP lies in the Kontum massif, which consists mainly of Archean granulite and ortho-
Project (ST2 HPP) in Vietnam.

\section{The Project}

The Song Tranh 2 Hydropower Project (ST2 HPP) is located on the Tranh River in Quang Nam province, Vietnam, approximately $100 \mathrm{~km}$ south-west of Danang. ST2 HPP is a multipurpose hydropower project with an installed capacity of $190 \mathrm{MW}$ and capacity to generate approximately 680 GWh energy annually. The project is comprised of a 96 meter high RCC gravity dam on a granite rock foundation. The construction of the RCC dam (figure 2) began in April 2008 and was completed in August 2011.

In addition to electricity production, ST2 HPP provides some flood control in the downstream areas and improves water supply to the downstream valley. Therefore, the project is strategically very important for reasons beyond hydro-electricity. The dam was proposed and constructed as having benefits to improve the socioeconomic status of the people living in the area while also increasing Vietnam's renewable energy production.

\section{The Project Geology}

Vietnam is located on two tectonic plates: the south China and Indochina plates. The plate boundary is the Red River fault zone that strikes northwest to southeast and extends over more than 1000 kilometers between the Gulf of Tonkin and Tibet. The Red River fault zone corresponds to two distinct structures: the Ailao Shan-Red River shear zone referring to the narrow metamorphic cores of the fault zone, and the active Red River fault system. The whole of the Indochina plate extrudes to the southeast during the collision of the Indian plate with Euro-Asian plate. Geologically, the territory of Vietnam can be divided into five units as structural blocks: northeast, northwest, Truongson, Kontum and Nambo, The

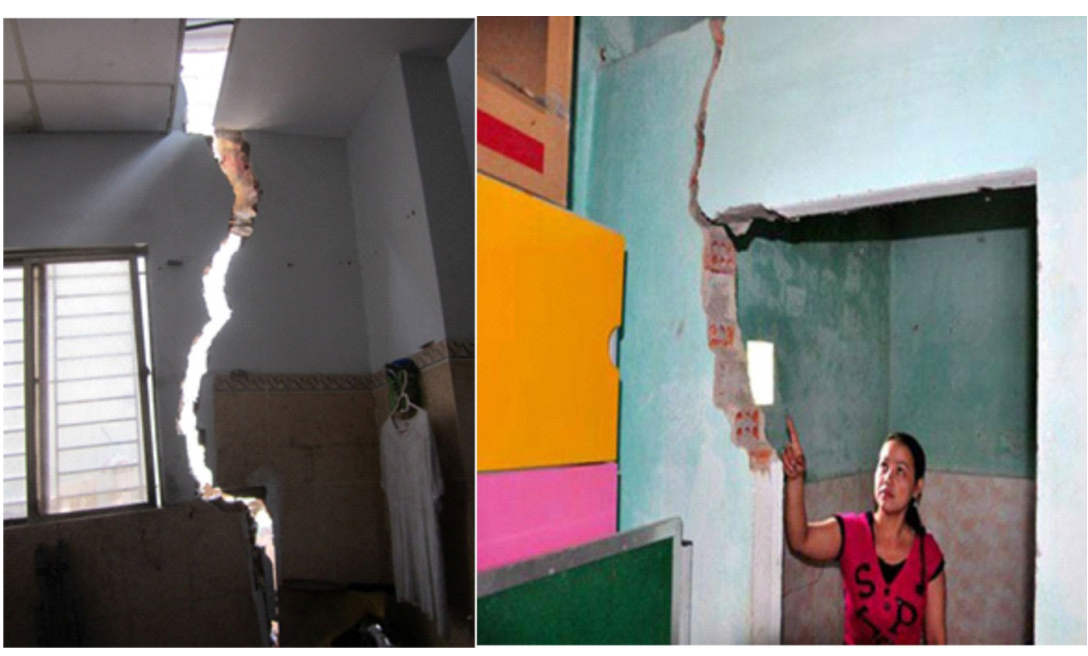

Figure 4: Damages in local homes, resulting from seismic activity at ST2 HPP. 
of many major and minor tectonic shear faults (figure 3).

As can be seen in figure 3, ST2 HPP lies between two major shear faults: the Tam Ky-Thouc Son and the Hung Nhuong-Ta Vi faults. In addition to these major faults, the area is influenced by numerous small scale faults and lineaments (red dot lines in the figure). In general, the granitic rock mass is massive, but fractured and of fairly good qualityto support an RCC dam.

\section{Reservoir Induced Seismic Activity}

Upon the advancement of the RCC dam construction, initial reservoir filling was completed by November 2010 and a reservoir elevation of $158 \mathrm{~m}$ amsl was reached. The dam was filled to $175 \mathrm{~m}$ amsl between October 2011 and March 2012. Months after the reservoir filling had been completed, a series of earthquake events occurred in the area. The intensity and magnitude of the earthquakes increased, causing concern from the local population and media. The seismic activity placed tremendous pressure upon both the project and local administration authorities. Initially, the authorities informed people that the seismic activity would be reduced after the filling, but more seismic activity followed. The authorities decided to reduce the water level in the reservoir in the belief that seismic activity in the area would also be reduced. However, even after this drawdown, even stronger seismic events continued. The credibility and trust in local dam authorities was lost. The seismic activity damaged many local homes and buildings (figure 4).

As a result, many local people left their villages from nearby the project area, and moved to the forests where they felt safer. Up to this point, Vietnam had experienced little seismic actvitity and this new phenomenon induced fear and confusion in many people. The public continued to debate the matter in the media. Each day following the seismic events, hundreds of articles and interviews were published, thus fueling greater chaos and question. Trinh (2012; first author) also contributed an article to this discussion, in which he tried to provide a technical view point to the public by explaining the incident in non-technical way.

In the following section, the authors tried to analyze seismic events qualitatively to presict the duture sesmic events. Now, after couple of years hasalready passed, the prediction that was made by Trinh (2012) was also reviewed and synthesized with the updated information received in 2014.

\section{Reservoir Level and Sseismic Events}

The reservoir filling elevation levels and seismic activities at the ST2 HPP for the period between November 2011 and September 2012 are presented in figure 5. We have attempted to analyze these earthquake events with the principle explained by Talwani (1997) as quotedabove.

There was no monitoring equipment at the ST2 HPP site to register the magnitude of seismic scale, so they were recorded qualitatively, using MSK-64 system. The MSK-64 scale or the Medvedev-Sponheuer-Karnik

\section{Medvedev-Sponheuer-Karnik Scale}

\begin{tabular}{|c|c|}
\hline Seismic scale & Shaking effect \\
\hline Not perceptible & $\begin{array}{l}\text { Not felt, registered only by seismographs. No ef- } \\
\text { fect on objects. No damage to buildings. }\end{array}$ \\
\hline $\begin{array}{l}\text { Hardly } \\
\text { perceptible }\end{array}$ & $\begin{array}{l}\text { Felt only by individuals at rest. No effect on ob- } \\
\text { jects. No damage to buildings. }\end{array}$ \\
\hline Weak & $\begin{array}{l}\text { Felt indoors by a few. Hanging objects swing } \\
\text { slightly. No damage to buildings. }\end{array}$ \\
\hline $\begin{array}{l}\text { Largely } \\
\text { observed }\end{array}$ & $\begin{array}{l}\text { Felt indoors by many and felt outdoors only by } \\
\text { very few. A few people are awakened. Moder- } \\
\text { ate vibration. Observers feel a slight trembling } \\
\text { or swaying of the building, room, bed, chair etc. } \\
\text { China glasses, windows and doors rattle. Hang- } \\
\text { ing objects swing. Light furniture shakes visibly } \\
\text { in a few cases. No damage to buildings. }\end{array}$ \\
\hline Fairly strong & $\begin{array}{l}\text { Felt indoors by most, outdoors by few. A few } \\
\text { people are frightened and run outdoors. Many } \\
\text { sleeping people awake. Observers feel a strong } \\
\text { shaking or rocking of the whole building, room } \\
\text { or furniture. Hanging objects swing consider- } \\
\text { ably. China glasses clatter together. Doors and } \\
\text { windows swing open or shut. In a few cases } \\
\text { window panes break. Liquids oscillate and may } \\
\text { spill from fully filled containers. Animals indoors } \\
\text { may become uneasy. Slight damage to a few } \\
\text { poorly constructed buildings. }\end{array}$ \\
\hline Strong & $\begin{array}{l}\text { Felt by most indoors and by many outdoors. A } \\
\text { few persons lose their balance. Many people } \\
\text { are frightened and run outdoors. Small objects } \\
\text { may fall and furniture may be shifted. Dishes } \\
\text { and glassware may break. Farm animals may be } \\
\text { frightened. Visible damage to masonry struc- } \\
\text { tures with cracks in plaster. Isolated cracks on } \\
\text { the ground. }\end{array}$ \\
\hline Very strong & $\begin{array}{l}\text { Most people are frightened and try to run out- } \\
\text { doors. Furniture is shifted and may be over- } \\
\text { turned. Objects fall from shelves. Water splash- } \\
\text { es from containers. Serious damage to older } \\
\text { buildings, masonry chimneys collapse. Small } \\
\text { landslides. }\end{array}$ \\
\hline Damaging & $\begin{array}{l}\text { Many people find it difficult to stand, even out- } \\
\text { doors. Furniture may be overturned. Waves may } \\
\text { be seen on very soft ground. Older structures } \\
\text { partially collapse or sustain considerable dam- } \\
\text { age. Large cracks and fissures opening up, rock } \\
\text { falls. }\end{array}$ \\
\hline Destructive & $\begin{array}{l}\text { General panic. People may be forcibly thrown } \\
\text { to the ground. Waves are seen on soft ground. } \\
\text { Substandard structures collapse. Substantial } \\
\text { damage to well-constructed structures. Under- } \\
\text { ground pipelines ruptured. Ground fracturing, } \\
\text { widespread landslides. }\end{array}$ \\
\hline Devastating & $\begin{array}{l}\text { Masonry buildings destroyed, infrastructure crip- } \\
\text { pled. Massive landslides. Water bodies may be } \\
\text { overtopped, causing flooding of the surrounding } \\
\text { areas and formation of new water bodies. }\end{array}$ \\
\hline Catastrophic & $\begin{array}{l}\text { Most buildings and structures collapse. Wide- } \\
\text { spread ground disturbances, tsunamis. }\end{array}$ \\
\hline $\begin{array}{c}\text { Very } \\
\text { catastrophic }\end{array}$ & $\begin{array}{l}\text { All surface and underground structures com- } \\
\text { pletely destroyed. Landscape generally changed, } \\
\text { rivers change paths, tsunamis. }\end{array}$ \\
\hline
\end{tabular}

Table 1: Brief descriptions of the seismic scale in the MSK-64 system (Wikipedia, 2014) 
scale is a macro-seismic intensity scale, which is used to qualitatively evaluate severity of ground shaking based on the observed effects in an area of earthquake occurrence (table 1).

Based on the reservoir filling and drawdown elevation and seismic events presented in figure 5, we have grouped the series of earthquake events into two groups:

Group 1: Seismic events that occurring between 23 November 2011 and 26 April 2012. Referring to Figure 5, one can see that the seismic events occurred after about 5 months from the start of reservoir filling.

Group 2: Seismic events that occurred between 29 August and 27 September 2012. This time span covers seismic events that occurred approximately five months after the start of the dewatering process for the reservoir.

Using Talwani's theory about the relationship between pore water pressure changes and seismic events, it would appear these two groups of seismic events may be directly linked to the process of increasing and decreasing water levels in the reservoir. If this is the case, two guidelines for adding and reducing water can be inferred: 1) If the change in reservoir water level is sufficiently large, the seismic event shall occur and it may happen after approximately five months from the time of the significant water level change in the reservoir; and 2) when the earthquake events do occur, the duration of such seismic series may extend for approximately 125 to 150 days.

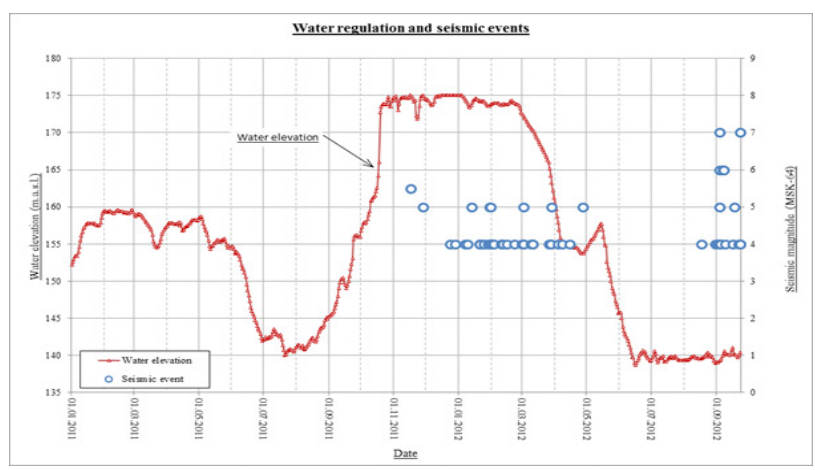

Figure 5: Water level and seismic events up to September 2012 (Institute of Geophysics 2012-2014) measured with a MSK-64 system

\section{Reconstructing the Seismic Scenario and Prediction}

Using our assessment above, which extends only to 2012, we further employ the MSK-64 seismic scale to assess seismic events occurring after 2012. Using the two qualitative hypothetical presented above, the seismic scenario at ST2 HPP is reconstructed as follows:

- $\quad$ From the day that filling the reservoir begins, water starts percolating into the rock mass and this alters the pore water pressure for the in-situ conditions. This process may happen rapidly or slowly depending on the permeability of the ground and the speed of water filling. At ST2 HPP, this alteration of pore-water pressure took roughly five months and the build-up of the pore-water pressure influenced the existing geological structures (faults and lineaments) located in the area as delineated in figure 3 , which lead to a noticeable movement in these structures, causing seismic events. This time duration (five months) is confirmed once again when a second earthquake group occurred about five months after the start of reservoir drawdown. It should be noted here that the water level drawdown also changes the pore-water pressure on the ground negatively. The ground will react to this change by trying moving back to their initial conditions or by creating a new equilibrium condition to adapt to the new in-situ stress condition on the ground.

- If the water level in the reservoir was kept stable, then seismic phenomena may reduce after about 125 to 150 days. However, due to concerns about safety of the local people as well as the safety of the structure (leakage through the body of the RCC dam), officials decided to drawdown the reservoir.

- Dewatering the reservoir may possibly have caused the second group of seismic events.

- We cannot conclude why earthquake intensities are of different scales during the reservoir filling and drawdown processes. This requires further discussion. As mentioned, earthquake scale depends on the scale of the impacted area and the change of pore-water pressure. Speeds of filling and drawdown were kept almost the same at ST2. However, a flood occurred right before the filling of the reservoir. This caused the reservoir water elevation to rise to approximately $160 \mathrm{~m}$ during 4 months. After that, the reservoir was drawn down for a short time and filling resumed (figure 5). It may be that the drawdown duration was not long enough to cause a significant change in pore-water pressure. Thus, if we account for the flood, the water filling speed of the reservoir was from 15 to 20 over 100 days ( $0.2 \mathrm{~m} /$ day). Meanwhile, the reservoir drawdown from elevation 175 $\mathrm{m}$ to a dead water level of $140 \mathrm{~m}$ also took about 100 days (35 m/day). Therefore, it may be possible that quicker drawdown rate caused higher intensity earthquakes.

- Looking more closely at figure 5 , we conclude that the stoppage time between two groups of earthquakes (more than 100 days) had the same duration as the reservoir water level stability at an elevation $175 \mathrm{~m}$. Thus, earthquakes may have occurred from the process of water level changing itself, and be less related to the high or low water levels in the reservoir. Assuming that if the reservoir was maintained at $175 \mathrm{~m}$ after the $23^{\text {rd }}$ February 2012, we can argue that the chances of depleting the seismic activities may have been depleted by $26^{\text {th }}$ April 2012 was there.

Can the future of seismic activity as it relates to reservoir projects be predicted? The Vietnamese government decided to halt water filling at ST2 HPP reservoir, and the reservoir was kept at $140 \mathrm{~m}$ for 17 months (figure 6). If our synthesized qualitative rules are assumed to be correct, the seismic event would have been reduced or have ceased after 125 to 150 days (the same duration as the seismic group 1). It means that the seismic events might have been reduced or stopped after January 2013. Verification of this hypothesis is presented in the following section. 


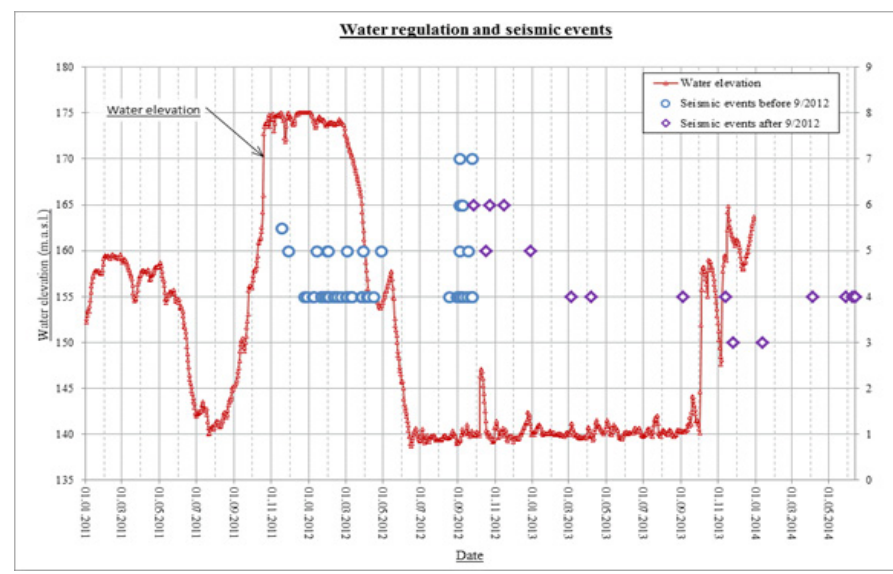

Figure 6: Water elevation and seismic events up to June 2014 (Institute of Geophysics, 2012-2014).

\section{The Seismic Scenario After One Year}

The water elevation and seismic event after the initial two groups of earthquakes at ST2 HPP were continued to be recorded. The recorded data of the seismic events and reservoir elevations are presented in figure 6.

Analyzing the data presented in Figure 6, we conclude the following:

- Even though water elevation in the reservoir was kept at minimum level (140 m amsl) for relatively long time (from July 2012 until October 2013), seismic activity did not completely cease. However, the intensity and frequency of occurrence of these events diminished considerably (figure 6).

- Seismic events with scale of 4 and lower in general draw less public attention since these small scale movements are typically not felt by many (Table 1 ). Thus, seismic events of 4 and less can be considered acceptable in terms of public safety. From this argument, it seems that the earlier prediction gives reasonable and acceptable result that seismic activity might have reduced or stopped after January 2013.

\section{Conclusion}

Reservoir-induced seismicity is a complicated phenomenon and very much depends on the specific geological and geo-hydrological conditions of a particular site. Our study concludes that there is certain degree of agreement on Talwani's hypothesis regarding pore water pressure, water reservoir levels, and seismic activity. Accordingly, we recommend that consistent monitoring of seismic activity and reservoir levels be conducted during all phases of filling and drawing down water levels. Furthermore, improved data collection is still needed for this subject. For example, it would be useful if the epicenter for each seismic event was identified and recorded. The geological structure of the area must be studied in greater detail, and the behavior of local geological structural responses against changes in the pore-water pressure also recorded. To reduce the seismic intensity at ST2 HPP, it is advisable to reduce the speed of water level change during filling and drawdown of the reservoir. Monitoring must be made continuously to map any reaction from the rock mass (ground) and to execute the necessary adjustments.

\section{Acknowledgements}

The authors would like to express their sincere thanks to colleagues and friends in Vietnam for providing data and information needed to expand the article published in local language in 2012.

Dr. Nghia Quoc Trinh, holds Ph.D. in Geological Engineering and MSc in Hydropower Engineering. He works as senior researcher at the 1SINTEF Building and Infrastructure, Trondheim, Norway. He is also Adjunct Associate Professor in numerical modeling at the Norwegian University of Science and Technology of NTNU. He has over 15 years of experiences in the fields of hydropower, tunneling, underground space technology, and mining technologies.

Email:nghia.quoc.trinh@sintef.no

Dr. Krishna Kanta Panthi, holds Ph.D. in Rock Engineering and MSc in Hydropower Engineering. He works as Associate Professor of Geological Engineering at the Department of Geology and Mineral Resources Engineering, Norwegian University of Science and Technology (NTNU), Norway. He has over 22 years of experience in tunneling, hydropower planning and design, construction management, and mining technologies.

Corresponding address: krishna.panthi@ntnu.co

\section{References}

Gupta, H.K., 2002, A review of recent studies of triggered earthquakes by artificial water reservoirs with special emphasis on earthquakes in Koyna, India, Earth-Science Reviews, 58, 279-310.

International Rivers, 2014, Map of reservoir caused earthquake regions, available at http://www.internationalrivers.org/ resources/google-earth-map-of-global-ris-sites-3554 (access on 24th June 2014).

Institute of Geophysics, 2012-2014, various publications on their website from 2012 to 2014 at http://www.igp-vast. vn/ (Vietnamese language).

Nam T. M. 1995. The Geology of Vietnam: the brief summary and problems. Geoscience Report. Shizuoka University, vol. 22, pp. 1-10.

Talwani, P., 1997, On the Nature of Reservoir-induced Seismicity, Pure applied Geophysics, 150, 473-492.

Trinh, N.Q., 2012, "Earthquake at Song Tranh 2 may relate to water regulation in the reservoir" published in public media in Vietnam.

Wikipedia, 2014, Medvedev-Sponheuer-Karnikscale, available at http://en.wikipedia.org/wiki/Medvedev\%E2 \%80\%93Sponheuer\%E2\%80\%93Karnik_scale 